\title{
Simulação hidráulico-hidrológica de dispositivos de baixo impacto na rede de drenagem da bacia do córrego Brejo Comprido em PALMAS/TO
}

O desenvolvimento proposto pela Low Impact Development (LID) envolve transformações profundas nos sistemas de drenagem. Palmas, a capital do Tocantins, tem enfrentado alagamentos ao longo dos anos por consequência da impermeabilização do solo decorrente da urbanização acelerada e das obras de ocupação que saturam o potencial de escoamento dos corpos hídricos. Dessa maneira, o objetivo deste trabalho foi simular a implantação de dispositivos LID relacionadas à drenagem urbana na bacia do Córrego Brejo Comprido, em Palmas - TO. A natureza da pesquisa é computacional com uso majoritário do SWMM. Os dispositivos de LID implantados nas simulações foram células de biorretenção e trincheiras de infiltração. A simulação de implantação das trincheiras e das células de biorretenção na microbacia do Brejo Comprido resultou em reduções nos volumes de escoamento do sistema de drenagem, houve redução de $48 \%$ na vazão na rede e de $50 \%$ no escoamento superficial.

Palavras-chave: Drenagem urbana; Dispositivos de baixo impacto; SWMM.

\section{Hydro-hydrological simulation of low impact devices in the microdrain network in the Brejo Comprido stream basin in Palmas/TO}

The development proposed by Low Impact Development (LID) involves profound changes in drainage systems. Palmas, the capital of Tocantins, has faced flooding over the years due to the impermeabilization of the soil resulting from the accelerated urbanization and the occupation works that saturate the potential of runof from water bodies. Thus, the objective of this work was to simulate the implantation of LID devices related to urban drainage in the Córrego Brejo Comprido basin, in Palmas - TO. The nature of the research is computational with a majority use of SWMM. The LID devices implanted in the simulations were bio-retention cells and infiltration trenches. The simulation of the implantation of trenches and bio-retention cells in the Brejo Comprido microbasin resulted in reductions in the flow volumes of the drainage system, with a $48 \%$ reduction in the flow in the network and a $50 \%$ reduction in the surface flow.

Keywords: Urban drainage; Low impact devices; SWMM

Topic: Tecnologia, Modelagem e Geoprocessamento

Reviewed anonymously in the process of blind peer.
Received: $\mathbf{0 3 / 1 2 / 2 0 2 0}$

Approved: 23/12/2020

Alesi Teixeira Mendes

Universidade Federal do Tocantins, Brasil

http://lattes.cnpq.br/2473113080999082

http://orcid.org/0000-0002-5632-7235

alesi atm@mail.uft.edu.br

Referencing this:

MENDES, A. T.. Simulação hidráulico-hidrológica de dispositivos de baixo impacto na rede de drenagem da bacia do córrego Brejo Comprido em PALMAS/TO. Revista Ibero Americana de Ciências Ambientais, v.11, n.7, p.752-760, 2020. DOI:

http://doi.org/10.6008/CBPC2179-6858.2020.007.0057 


\section{INTRODUÇÃO}

Nos últimos anos, por consequência do crescimento das cidades e do aumento acentuado das áreas impermeabilizadas, diversos países têm enfrentado problemas de inundações urbanas e de alagamentos decorrentes do envelhecimento e obsolescência dos sistemas de drenagem urbana. As regiões metropolitanas de Baltimore e Houston, nos Estados Unidos (NASEM, 2019); Dublin, a capital da Irlanda (LHOMME et al., 2019); e várias cidades na China (BAl et al., 2018), enfrentaram esses problemas.

O início do ano de 2020 no Brasil foi marcado pela ocorrência de chuvas torrenciais que ocasionaram inundações em cidades como Belo Horizonte, São Paulo e Rio de Janeiro. Esse problema não é pontual e tem se repetido ao longo dos anos, e não apenas nas grandes e densamente urbanizadas cidades brasileiras, mas também nas novas e em processo de ocupação. Palmas, a capital do Tocantins e última cidade planejado do país, apesar de não registrar problemas com inundações e enchentes, têm enfrentado alagamentos ao longo dos anos por consequência da impermeabilização do solo e da sobrecarga da rede de drenagem (PALMAS, 2014).

Diante desse cenário a adoção de sistemas de drenagem que recuperam e ampliam a capacidade de retenção, absorção e infiltração de águas pluviais no solo, e que há algumas décadas já vem sendo implantados em países desenvolvidos, têm sido estudadas e incentivadas em algumas cidades brasileiras (TUCCI, 2003).

Contudo, tanto a análise quanto à adequação de um sistema urbano de drenagem são tarefas complexas, e uma alternativa na elaboração de possíveis cenários nos quais medidas sustentáveis são aplicadas permitindo analisar o comportamento da bacia hidrográfica e os benefícios, ou malefícios, dessas medidas é a modelagem hidráulico-hidrológica.

Atualmente estão à disposição dos profissionais uma grande gama de programas que realizam simulações hidráulico-hidrológicas: Storm Water Management Model (SWMM), série IPH, série HEC, MOUSE, SMAP, ILLUDAS. Do conjunto de programas utilizados para simulações de redes de drenagem urbana um número expressivo de trabalhos em bacias urbanizadas se utilizou do SWMM em suas análises. Cumpre mencionar os estudos de Vinagre et al. (2015) que estudaram o comportamento hidráulico do sistema de drenagem da Bacia do Paracuri, no município de Belém - PA; o trabalho de Silva Júnior et al. (2017) quanto a utilização de alternativas compensatórias de drenagem urbana, utilizando o modelo SWMM para o ponto crítico de alagamento numa área urbana e vulnerável as oscilações de maré, em Recife - PE, com base nas informações cadastrais da rede de microdrenagem. E, por sua vez, Fileni et al. (2019) que simularam a implantação de dispositivos LID em áreas urbanas já consolidadas do Distrito Federal.

A capital tocantinense tem procurado mudar esse cenário inclusive na revisão de seu Plano Diretor que procura aliar a sustentabilidade à gestão da drenagem do município, incentivando a adoção dos sistemas de drenagem sustentável em área urbana em complemento à drenagem artificial. Assim, o estudo de medidas menos impactantes para o manejo de águas pluviais é exigência legal e não apenas uma alternativa para os problemas enfrentados na cidade. Deste modo, o objetivo principal desse trabalho é simular a 
implantação de dispositivos de Desenvolvimento de Baixo Impacto (low impact development, LID) na bacia do Córrego Brejo Comprido, em Palmas - TO e avaliar a possível redução de vazão nas redes de microdrenagem.

\section{METODOLOGIA}

A área urbana da bacia representa um percentual de $43,85 \%$ de sua área total, medindo $20,21 \mathrm{~km}^{2} \mathrm{e}$ com um perímetro de 29,02 km. O talvegue do Córrego Brejo Comprido possui 7,48 km e a microbacia apresenta amplitude de 76,95 m, o que the confere uma declividade média de 1,02\%.

A delimitação da bacia partiu de um Modelo Digital de Terreno (MDT) gerado a partir de um levantamento planialtimétrico fornecido pela Secretaria de Infraestrutura e Obras de Palmas, com curvas de nível de metro a metro da área urbana da cidade e as bacias urbanas de drenagem subdivididas nas simulações com base na divisão das bacias de contribuição do cadastro de drenagem municipal, levando em consideração as características de relevo e o traçado da malha viária da cidade.

A caracterização do uso e ocupação do solo foi feita por meio da análise da classificação supervisionada de uma imagem de alta resolução da área de estudo, pelo método de máxima verossimilhança (MAXVER). A imagem utilizada na classificação é do satélite Plêiades do ano de 2015, com resolução espacial de $0,50 \mathrm{~m}$, resolução radiométrica de 8 bits por célula e composição colorida em 3 bandas (red, green e blue).

A precisão da classificação foi determinada por meio da matriz de confusão e pelo cálculo do Índice Kappa. Esse índice estatístico mede o grau de concordância entre proporções derivadas de amostras dependentes. Quando aplicado na classificação de imagens apresenta o quanto à classificação está de acordo com os dados de referência (SILVA et al., 2012). Hasan et al. (2012), Marteli et al. (2015) e Casapia et al. (2020) utilizam o coeficiente em seus trabalhos.

O índice Kappa foi calculado por meio da Equação 1, com os valores de observações encontrados na matriz de confusão.

$$
k=\frac{k_{1}-k_{2}}{1-k_{2}}
$$

Onde:

k1: razão entre os pares de observações concordantes e o número total de observações; k2: é a soma das probabilidades de em ambas as classificações as células serem classificadas igualmente. A Tabela 1 apresenta os intervalos de avaliação do índice Kappa.

Tabela 1: Valor para avaliar o grau de concordância a partir do índice Kappa

\begin{tabular}{ll}
\hline Valor do Kappa & Concordância \\
\hline$<0,20$ & Pobre \\
$0,21-0,40$ & Fraca \\
$0,41-0,60$ & Moderada \\
$0,61-0,80$ & Boa \\
$0,81-1,00$ & Muito boa
\end{tabular}

Fonte: Silva et al. (2012).

As atribuições das classes de uso do solo foram baseadas na metodologia do SCS (USDA, 1986). A Prefeitura Municipal de Palmas realizou um levantamento pedológico do município, no qual os solos da 
região de estudo foram classificados como latossolo vermelho-amarelo. Desta maneira, seguindo a classificação do método SCS Curve Number o solo da bacia foi enquadrado no grupo hidrológico B.

A cobertura vegetal e foi dividida em três grupos distintos: áreas com vegetação, campos abertos sem vegetação e áreas impermeabilizadas. E adotados os seguintes valores de CN: áreas com vegetação com CN igual a 61, campos abertos sem vegetação e CN igual a 69, e áreas impermeabilizadas com CN igual a 98 (Figura 1).

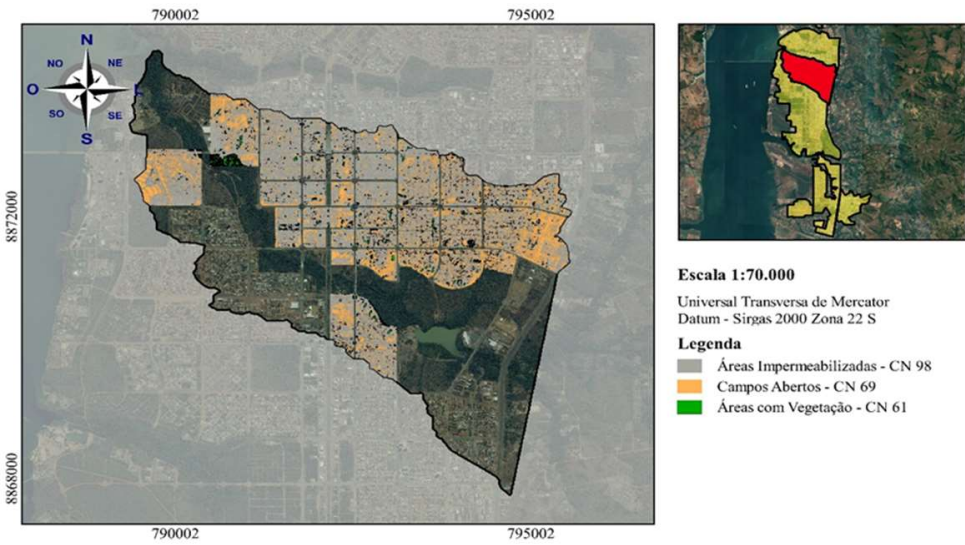

Figura 1: Mapa da classificação da cobertura do solo.

A acurácia da classificação foi determinada por meio da matriz de confusão. A Tabela 2 apresenta a matriz de confusão, na qual do total de 23.288 observações 21.209 , cerca de $91,07 \%$, são concordantes.

Tabela 2: Matriz de confusão

\begin{tabular}{lllll}
\hline Classificação & Áreas com Vegetação & $\begin{array}{l}\text { Áreas } \\
\text { Impermeabilizadas }\end{array}$ & Campos Abertos & Total \\
\hline Áreas com Vegetação & $\mathbf{2 6 4 7}$ & 423 & 214 & 3284 \\
Áreas Impermeabilizadas & 326 & $\mathbf{1 0 2 3 8}$ & 756 & 11320 \\
Campos Abertos & 129 & 231 & $\mathbf{8 3 2 4}$ & 8684 \\
Total & 3102 & 10892 & 9294 & 23288 \\
\hline
\end{tabular}

O Índice Kappa encontrado com o resultado da matriz é igual a 0,85. O grau de concordância da classificação é muito bom segundo os intervalos propostos por Silva et al. (2012).

A precipitação de projeto foi determinada a partir da equação Intensidade-Duração-Frequência (IDF) de Andrade (2014), que estimou em sua pesquisa os valores dos coeficientes da equação de chuvas intensas para Palmas -TO. A Equação 2, a seguir, é resultado dos estudos do autor.

$$
i=\frac{884,669 x T^{0,156}}{(t+9,884)^{0,726}}
$$

Onde: i: intensidade máxima de chuva $\left(\mathrm{mm} \cdot \mathrm{h}^{-1}\right)$; $\mathrm{T}$ : período de retorno (anos); e

$\mathrm{t}$ : duração da chuva (min).

O tempo de retorno adotado foi de 25 anos, usualmente utiliza-se valores menores para sistemas de microdrenagem, todavia essa bacia abrange quase todo o Plano Diretor Central da cidade, numa área bastante consolidada do perímetro urbano e que possui diversos serviços essenciais, como hospitais, maternidades e unidades de saúde comunitária.

O tempo de duração da chuva de projeto foi considerado igual ao tempo de concentração (Tc) e calculado por meio da equação de Kirpich, a seguir (Equação 3): 


$$
T c=57 x\left(\frac{L^{3}}{H}\right)^{0,385}
$$

Quanto os coeficientes de Manning para parcelas permeáveis e impermeáveis adotou-se respectivamente como 0,011 e 0,15 valores característicos de superfícies de gramado curto e asfalto liso (ROSSMAN, 2010). O lançamento da rede de microdrenagem no SWMM seguiu o Cadastro de Drenagem Urbana do Município, fornecido pela Secretaria de Infraestrutura e Serviços Públicos de Palmas, com atualização em 2017. Nesse cadastro estão contidas as informações referentes as redes de drenagem de Palmas: extensão das tubulações, diâmetro, comprimento, profundidade e inclinação dos trechos, profundidade dos PV, e as cotas de terreno. Da rede total de drenagem de Palmas contida no cadastro, foi inserido nas simulações um total de 17,33 km.

Os dispositivos de LID implantados nas simulações foram células de biorretenção e trincheiras de infiltração. As trincheiras e células de biorretenção foram dimensionadas levando em consideração a equação IDF de Andrade 2014 (Equação 1) para o mesmo tempo de retorno da chuva de projeto.

Cada trincheira foi dimensionada com extensão de 100 metros a intervalos de 3,0 m entre uma e outra. Nas simulações foram consideradas trincheiras com profundida de 1,5 m e admitiu-se uma taxa de infiltração constante.

A geometria adotada para as células de biorretenção foi circular, e respeitando as recomendações da literatura: área máxima inferior a $800 \mathrm{~m}^{2}$ e até $4 \%$ do tamanho da área impermeável a ser drenada (WOODS-BALLARD et al., 2015).

\section{RESULTADOS E DISCUSSÃO}

A simulação da condição do sistema de microdrenagem sem os dispositivos LID apontou escoamento superficial de pico na terceira hora transcorrida e com vazão de cerca de $44,85 \mathrm{~m}^{3} \cdot \mathrm{s}^{-1}$. Com relação à capacidade, de modo geral, o sistema de microdrenagem da microbacia opera abaixo da sua capacidade máxima durante a maior parte da chuva de projeto, mesmo no período de escoamento crítico.

O problema reside nos trechos iniciais das redes de drenagem que, diferentemente das galerias principais, são compostas em sua maioria por condutos com diâmetro relativamente pequeno, variando entre 0,60 e 0,80 m. Esses trechos recebem o escoamento proveniente das quadras, contudo devido aos elevados percentuais de impermeabilização os volumes escoados para essas redes são também elevados.

A Figura 2 apresenta a capacidade da rede no momento de escoamento crítico. As cores dos trechos indicam a capacidade em que estão operando, alternando do azul-escuro que indica operação abaixo dos $25 \%$ até o vermelho que indica operação em $100 \%$ da capacidade.

Como os trechos iniciais da rede não tem a capacidade de captar e transportar o escoamento, as águas pluviais são conduzidas nas próprias vias, em grande parte, no sentido da Av. Teotônio Segurado que, embora seja umas das principais da capital, não possui um sistema de captação de águas pluviais adequado. 
A Tabela 3 apresenta os condutos que durante o período da chuva de projeto tem sobrecarga em sua capacidade.

Tabela 3: Síntese da sobrecarga nos condutos (em horas).

\begin{tabular}{llllll}
\hline \multirow{2}{*}{ Condutos } & Horas (cheio) & \multicolumn{2}{c}{ Horas Fluxo Acima do Normal } & Horas Capacidade Limitada \\
\cline { 2 - 5 } & Ambas Extremidades & Montante & Jusante & & 1,25 \\
TC1 & 1,22 & 1,25 & 1,22 & 1,27 & 0,19 \\
TC39 & 0,13 & 0,19 & 0,13 & 0,06 & 0,48 \\
TC40 & 0,44 & 0,48 & 0,45 & 0,05 & 0,26 \\
TC89 & 0,22 & 0,26 & 0,22 & 0,05 & 0,67 \\
TC187 & 0,65 & 0,67 & 0,66 & 0,03 & 0,01 \\
TC189 & 0,01 & 0,01 & 0,01 & 0,02 & 0,45 \\
TC201 & 0,37 & 0,45 & 0,38 & 1,14 & 0,1 \\
TC241 & 0,01 & 0,1 & 0,01 & 0,1 & 0,44 \\
TC242 & 0,41 & 0,44 & 0,41 & 0,44 & 0,09 \\
TC245 & 0,01 & 0,09 & 0,01 & 0,09 & 0,55 \\
TC247 & 0,51 & 0,55 & 0,51 & 0,05 & \\
\hline
\end{tabular}

No tocante a velocidade, se o valor de referência adotado como velocidade máxima admissível é de 5,0 m.s $\mathrm{s}^{-1}$, seguindo a recomendação de Menezes Filho et al. (2012) e do Município de São Paulo (FCTH, 1999), cerca de $15 \%$ das tubulações da rede de microdrenagem estão operando acima da velocidade máxima. Se o valor adotado for 4,0 m.s $\mathrm{s}^{-1}$ proposto pelo Departamento de Esgotos e Águas Pluviais de Porto Alegre (PORTO ALEGRE, 2005) cerca de 33\% da rede opera acima da velocidade máxima.

Na nova simulação, em que foi prevista a implantação de dispositivos LID na bacia, o pico de escoamento continua próximo da terceira hora transcorrida. Não obstante, a simulação apresenta uma redução de $48,11 \%$ no pico do escoamento que antes superava os $44 \mathrm{~m}^{3} \cdot \mathrm{s}^{-1}$ e agora se mantém nos 23,27 $\mathrm{m}^{3} \cdot \mathrm{s}^{-1}$. Apenas 5 trechos no total apresentam sobrecarga no momento dos escoamentos críticos, diferente dos 11 trechos da simulação anterior (Figura 3).

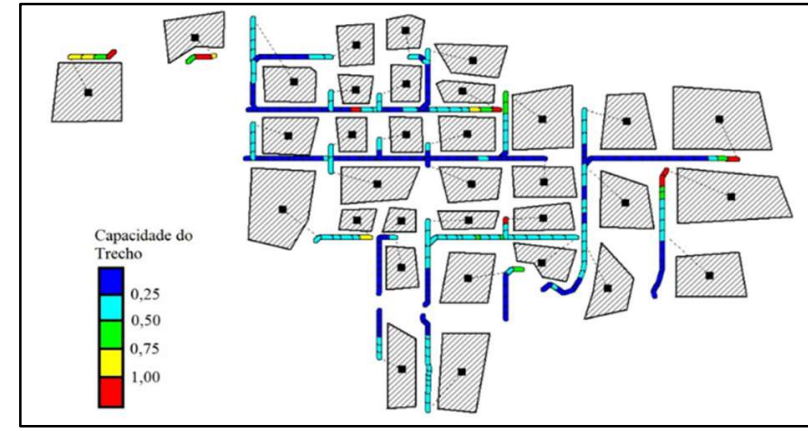

Figura 2: Capacidade dos trechos da rede com LID.

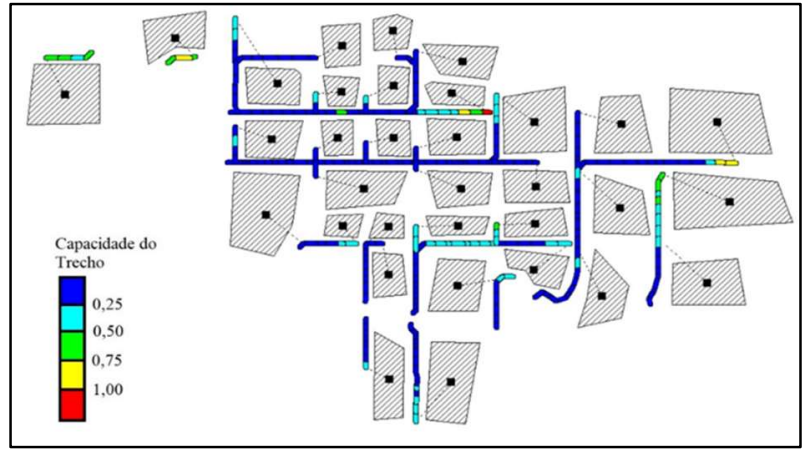

Figura 3: Capacidade dos trechos da rede com LID.

A Tabela 4 abaixo apresenta a síntese da vazão de alguns trechos representativos do sistema de drenagem da microbacia do Córrego Brejo Comprido nas duas simulações.

Tabela 4: Síntese da vazão dos trechos.

\begin{tabular}{|c|c|c|c|c|c|c|c|}
\hline & Sem LID & & & Com LID & & & \\
\hline Trecho & $\begin{array}{l}\text { Vazão } \\
\text { Máxima } \\
\left(\mathrm{m}^{3} \cdot \mathrm{s}^{-1}\right)\end{array}$ & $\begin{array}{l}\text { Velocidade } \\
\text { Máxima } \\
\left(\mathrm{m} . \mathrm{s}^{-1}\right)\end{array}$ & $\begin{array}{l}\text { Altura de Lâmina } \\
\text { Máxima } \\
\text { (m) }\end{array}$ & \begin{tabular}{|l|} 
Vazão \\
Máxima \\
$\left(\mathrm{m}^{3} \cdot \mathrm{s}^{-1}\right)$
\end{tabular} & $\begin{array}{l}\text { Velocidade } \\
\text { Máxima } \\
\left(\mathrm{m} \cdot \mathrm{s}^{-1}\right)\end{array}$ & $\begin{array}{l}\text { Altura de } \\
\text { Máxima } \\
\text { (m) }\end{array}$ & Lâmina \\
\hline TC65 & 0,67 & 3,02 & 0,33 & 0,33 & 2,48 & 0,23 & \\
\hline TC66 & 0,67 & 3,27 & 0,31 & 0,33 & 2,68 & 0,22 & \\
\hline TC64 & 0,67 & 2,82 & 0,34 & 0,33 & 2,31 & 0,24 & \\
\hline TC67 & 0,67 & 2,65 & 0,36 & 0,33 & 2,17 & 0,25 & \\
\hline
\end{tabular}




\begin{tabular}{|c|c|c|c|c|c|c|}
\hline TC63 & 0,68 & 3,27 & 0,43 & 0,34 & 2,70 & 0,30 \\
\hline TC62 & 0,68 & 3,14 & 0,44 & 0,34 & 2,60 & 0,31 \\
\hline TC114 & 1,34 & 3,34 & 0,17 & 0,67 & 2,74 & 0,12 \\
\hline TC111 & 1,34 & 5,42 & 0,20 & 0,67 & 4,43 & 0,14 \\
\hline TC112 & 1,34 & 4,15 & 0,15 & 0,67 & 3,26 & 0,11 \\
\hline TC113 & 1,34 & 4,21 & 0,15 & 0,67 & 3,31 & 0,11 \\
\hline TC110 & 1,35 & 5,21 & 0,20 & 0,67 & 4,25 & 0,14 \\
\hline TC109 & 1,35 & 5,14 & 0,28 & 0,67 & 4,21 & 0,20 \\
\hline TC108 & 1,35 & 4,63 & 0,30 & 0,67 & 3,80 & 0,21 \\
\hline TC107 & 1,35 & 3,55 & 0,37 & 0,67 & 2,92 & 0,26 \\
\hline TC20 & 1,57 & 1,70 & 0,21 & 0,79 & 1,38 & 0,15 \\
\hline
\end{tabular}

A Tabela 5 apresenta o percentual de redução dos diferentes parâmetros apresentados acima. Houve redução de até $50 \%$ na vazão máximo na rede de drenagem e de 30\% na profundidade da lâmina de água.

Tabela 5: Percentual de redução nas simulações.

\begin{tabular}{llll}
\hline Trecho & $\begin{array}{l}\text { Redução Vazão Máxima } \\
\text { (\%) }\end{array}$ & $\begin{array}{l}\text { Redução Velocidade Máxima } \\
\text { (\%) }\end{array}$ & $\begin{array}{l}\text { Redução Altura de Lâmina Máxima } \\
\text { (\%) }\end{array}$ \\
\hline TC65 & 50,31 & 17,88 & 30,30 \\
TC66 & 50,31 & 18,04 & 29,03 \\
TC64 & 50,29 & 18,09 & 29,41 \\
TC67 & 50,29 & 18,11 & 30,56 \\
TC63 & 50,28 & 17,43 & 30,23 \\
TC62 & 50,26 & 17,20 & 29,55 \\
TC114 & 49,98 & 17,96 & 29,41 \\
TC111 & 49,98 & 18,27 & 30,00 \\
TC112 & 49,98 & 21,45 & 26,67 \\
TC113 & 49,98 & 21,38 & 26,67 \\
TC110 & 49,97 & 18,43 & 30,00 \\
TC109 & 49,97 & 18,09 & 28,57 \\
TC108 & 49,97 & 17,93 & 30,00 \\
TC107 & 49,96 & 17,75 & 29,73 \\
TC20 & 49,85 & 18,82 & 28,57 \\
\hline
\end{tabular}

Os dispositivos LID implantados na simulação mitigaram parte dos efeitos da impermeabilização compensando-os com o aumento pontual da infiltração no solo, contudo não solucionaram inteiramente o problema da sobrecarga na rede no momento de escoamento de pico. Outros autores já chegaram a esse ponto comum.

Em trabalho desenvolvido por Silva Júnior et al. (2017), os autores constataram que apesar de a implantação de dispositivos LID nas redes de drenagem reduzirem as áreas de alagamento, elas não resolveriam integralmente os problemas de alagamentos locais, apenas atenuariam e aumentariam a sobrecarga dos condutos a jusante do sistema modificado.

Damodaram et al. (2010), concluíram que os dispositivos LID nas redes de drenagem são mais eficientes nos eventos de menor intensidade, mas apresentam um controle menor nos eventos de inundação.

No tocante a velocidade, embora tenham ocorrido reduções de até $13 \%$ em alguns trechos da rede de microdrenagem, durante o pico do escoamento a velocidade em $16 \%$ da rede continua superior aos 4,0 $\mathrm{m} . \mathrm{s}^{-1}$ proposto pelo Departamento de Esgotos e Águas Pluviais de Porto Alegre (DEP/IPH, 2005) e aos 5,0 m.s ${ }^{1}$ admitidos por Menezes Filho et al. (2012) e pelo Município de São Paulo (FCTH, 1999). 


\section{CONCLUSÕES}

Uma alternativa para evitar a impermeabilização excessiva em futuras áreas da cidade é a elaboração de uma Política de Drenagem Urbana Sustentável, que regulamente a drenagem urbana do município incentivando a infiltração das águas pluviais, que estabeleça limites para impermeabilização das propriedades públicas e privadas, e critérios para a sua distribuição no tempo e no espaço, por exemplo, estabelecendo valores máximos de vazão nas saídas dos lotes. Nas regiões já impermeabilizadas, a alternativa é a implantação de dispositivos estruturais que promovam a infiltração das águas pluviais na fonte.

Nas simulações propostas, a implantação de dispositivos LID foi uma alternativa pontual de aumento de infiltração no sistema de microdrenagem, houve considerável diminuição nas vazões nas tubulações, na profundidade das lâminas de água nos condutos e na velocidade do escoamento.

As medidas implantadas na simulação são, de fato, eficientes na compensação dos problemas oriundos da urbanização, principalmente a impermeabilização dos solos. São medidas pontuais que, mesmo representando uma área pequena da microbacia, aumentam sua capacidade de infiltração.

Porém, seria ideal que essas medidas deixassem de ser apenas compensatórias e passassem a ser integradas ao planejamento e desenvolvimento urbano da cidade, a fim alcançar um crescimento urbano hidrologicamente funcional e sustentável.

\section{REFERÊNCIAS}

BAI, Y.; ZHAO, N.; ZHANG, R.; ZENG, X.. Storm Water Management of Low Impact Development in Urban Areas Based on SWMM. Water, v.11, n.1, p.1-16, 2018. DOI: https://doi.org/10.3390/w11010033

CASAPIA, X. T.; FALEN, L.; BARTHOLOMEUS, H.; CÁRDENAS, R.; FLORES, G.; HEROLD, M.; CORONADO, E. N. H.; BAKER, T. R.. Identifying and Quantifying the Abundance of Economically Important Palms in Tropical Moist Forest Using UAV Imagery. Remote Sensing, v.12, n.9, p.1-16, 2020. DOI: https://doi.org/10.3390/rs12010009

DAMODARAM, C.; GIACOMONI, M. H.; KHEDUN, C. P.; HOLMES, H.; RYAN, A.; SAOUR, W.; ZECHMAN, E. M.. Simulation of Combined Best Management Practices and Low Impact Development for Sustainable Stormwater Management. Journal of the American Water Resources Association, v.46, n.5, p.907-918, 2010. DOI: https://doi.org/10.1111/j.1752-1688.2010.00462.x

FILENI, F. M.; COSTA, M. E. L.; ALVES, C. M. A.. The application of LIDs in Savanna region for mitigation of flooded areas. Revista Brasileira de Recursos Hídricos, Porto Alegre, v.24, n.40, 2019. DOI: https://doi.org/10.1590/2318$\underline{0331.241920180177}$

HASAN, R. C.; IERODIACONOU, D.; MONK, J.. Evaluation of Four Supervised Learning Methods for Benthic Habitat Mapping Using Backscatter from Multi-Beam Sonar. Remote Sensing, v.4, n.11, p.3427-3443, 2012. DOI: https://doi.org/10.3390/rs4113427

LHOMME, S.; LAGANIER, R.; DIAB, Y.; SERRE, D.. The resilience of the city of Dublin to flooding: from theory to practice. European Journal of Geography, n.651, 2019. DOI: https://doi.org/10.4000/cybergeo.33480

MARTELI, A. N.; PIROLI, E. L.. Análise do desempenho de interpoladores para a elaboração de mapas de $\mathrm{pH}$ para a agricultura familiar. Brazilian Journal of Applied Technology for Agricultural Science, Guarapuava, v.8, n.2, p.87-98, 2015. DOI: https://doi.org/10.5935/PAeT.V8.N2.10

MENEZES FILHO, F. C. M. M.; COSTA, A. R.. Verificação do dimensionamento das galerias de águas pluviais em uma sub-bacia do Córrego Botafogo na cidade de Goiânia - GO. Revista Eletrônica de Engenharia Civil, v.4, n.1, p.1-11, 2012.

NASEM. National Academies of Sciences, Engineering, and Medicine. Framing the Challenge of Urban Flooding in the United States. Washington: The National Academies Press, 2019. DOI: https://doi.org/10.17226/25381

PALMAS. Prefeitura Municipal de Palmas. Plano Municipal de Saneamento Básico de Palmas - TO. Anexo III ao Decreto no 700, de 15 de janeiro de 2014. v.III: Drenagem Urbana. Palmas: DOE, 2014.

PORTO ALEGRE. Departamento de Esgotos e Águas Pluviais de Porto Alegre. Departamento de Esgotos Pluviais. Plano Diretor de Drenagem Urbana. Manual de Drenagem Urbana. 2 ed. Porto Alegre: Departamento de Esgotos e Águas Pluviais de Porto Alegre, 2005.

ROSSMAN, L. A.. Manual do usuário - EPA SWMM 5.0: Modelo de Gestão de Drenagem Urbana. Brasilia: UFPB, 2010. 
SILVA JUNIOR, M. A. B.; SILVA, S. R.; CABRAL, J. J. S. P.. Compensatory alternatives for flooding control in urban areas with tidal influence in Recife - PE. Revista Brasileira de Recursos Hídricos, Porto Alegre, v.22, n.19, 2017. DOI: https://doi.org/10.1590/2318-0331.011716040

SILVA, R. S.; PAES, A. T.. Teste de concordância Kappa. Educação Continuada em Saúde Einstein, v.10, n.4, p.165166, 2012.

TUCCI, C. E. M.. Águas urbanas. In: TUCCI, C. E. M. BERTONI,
J. C.. Inundações Urbanas na América do Sul. Porto Alegre: ABRH, 2003.

VINAGRE, M. V. A.; LIMA, A. C. M.; LIMA JUNIOR, D. L.. Estudo do comportamento hidráulico da Bacia do Paracuri em Belém (PA) utilizando o programa Storm Water Management Model. Eng. Sanit. Ambient., Rio de Janeiro, v.20, n.3, p.361-368, 2015. DOI:

https://doi.org/10.1590/S1413-41522015020000106515

WOODS-BALLARD, B.. The SuDS Manual. CIRIA, 2015

A CBPC - Companhia Brasileira de Produção Científica (CNPJ: 11.221.422/0001-03) detém os direitos materiais desta publicação. Os direitos referem-se à publicação do trabalho em qualquer part do mundo, incluindo os direitos às renovações, expansões e disseminações da contribuição, bem como outros direitos subsidiários. Todos os trabalhos publicados eletronicamente poderão posteriormente ser publicados em coletâneas impressas sob coordenação da Sustenere Publishing, da Companhia Brasileira de Produção Científica e seus parceiros autorizados. Os (as) autores (as) preservam os direitos autorais, mas não têm permissão para a publicação da contribuição em outro meio, impresso ou digital, em português ou em tradução. 